\title{
What rules to frame the development of new vineyards plots in Bandol DOP?
}

\author{
Paul Minvielle ${ }^{1}$, Loïc Villier ${ }^{2}$ and Jacques Daligaux ${ }^{1}$, Stéphane Angles ${ }^{3}$ \\ ${ }^{1}$ Aix Marseille Univ, CNRS, TELEMME, Aix-en-Provence, France \\ ${ }^{2}$ Pierre and Marie Curie University - Paris 6, Paris UPMC, France \\ ${ }^{3}$ Université de Lorraine, EA LOTERR, Nancy, France
}

Resumen. The vineyard of Bandol is confronted with an important land pressure in a very urbanized and very touristic area. The new parcels that appear at the northern edge of the vineyard must comply with a certain number of rules in order to maintain the quality and typicality of the wines.

\section{Introduction}

Since 1935, l'INAO, Institut National de l'Origine et de la qualité, delimits terroirs, in France, at the plots fine scale, relying on geological and pedological criteria. The boundaries of the Bandol vineyard date from 1941 and considers the territory of 8 communes of Var department, except the lowest areas, covered with alluvial formations, (figure 1). Diversity and mapping of wine terroirs have been analyzed in a precedent study, under the prism of the expressions of soil and geological substrate properties in the Bandol red wines. [1].

The paper proposes first to define Bandol terroir using Warren Moran approach [2], then to deal with the question of the valorization of soils from the point of view of its legal zoning, its delimitation parcellaire. We consider the development of agricultural land-use planning and the durability of the strategies of a qualitative wine production with strong identity. Plots planted with vines cover about 1500 hectares, preferentially implanted on sandy-clay soils rich in limestone.



Figure 1. Bandol DOP localization

Large areas not planted, mainly forested, extend in the northern part of the area. This territory is generally on medium to steep slopes, on compact limestones of the Upper Cretaceous. For several decades, viticulture practices have consisted in developing these forested areas, often to compensate for losses suffered by the vine in the lower parts, gradually consumed by urbanization. These developments took the form of land clearing and then development of plots, crushing and grinding of the hardest surface horizons and terracing. These practices that were long tolerated, while they modified the original terroir, are today problematic to professionals and authorities in charge of vineyard management.

\section{Bandol an archetypal terroir}

Bandol DOP is a quiet archetypal territory to illustrate a terroir in the meaning of the French National Institute of Origin and Quality (INAO): that is to say: a "terroir is a delimited geographical space, in which a human community built, in the course of its history, a collective knowledge of production, based on a system of interactions between a physical and biological environment and a set of human factors". [3]. We are going to precise first the agro/vini terroir dimension, then complete with social terroir aspects, according to Warren Moran approach. It is important to reaffirm the need for an interdisciplinary approach for terroir studies, including pedologists, climatologists, agronomists, oenologists, but also sociologists, lawyers, geographers... (figure 2) 


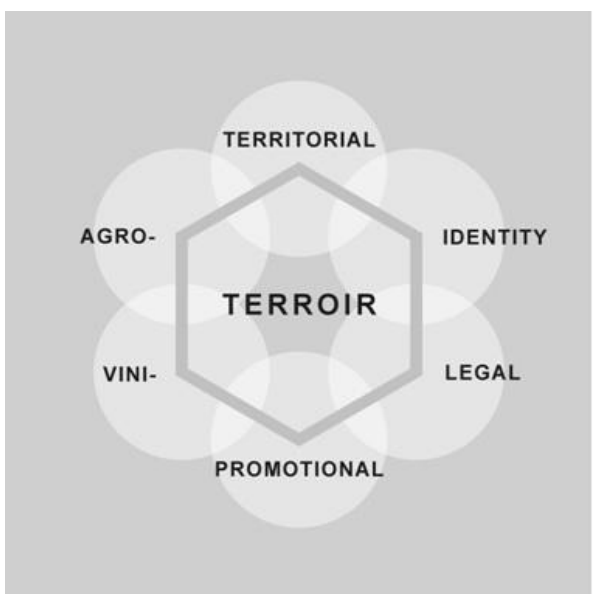

Figure 2. Warren Moran approach of terroir (2006, op.cit.)

\subsection{The agro/vini terroir}

Bandol is famous for red wines that differentiate from other French appellations using the Mourvèdre grape at a minimum of $50 \%$ of the blends. Historically, the strategy developed by the local wine producers and regulation authorities was too emphasize the high quality and typicality of the red wines. The average high quality relies on high constraints imposed for the AOC label. The initial delimitation in 1941 is justified by the history of wine production, the current practices and spatial partitioning of high and poor-quality products, and the zonation was subdued to a geological study. The definition of the appellation considered geology only for exclusion of the low land vineyards that grow on recent alluvial deposits, and that were dedicated to low quality, highly productive grapes. The statutory order of the A.O.C. revised in 2011 cites geological criteria only in an historical perspective, although the limits initially placed according to the borders of geological units are retained.

The question arises of how the geological substrate and soil properties may deserve justification of the Appellation boundaries. The geological substrate and soil properties vary spatially within the appellation and their incidence on wine typicality remains difficult to demonstrate. We hereby present a preliminary assessment of a potential terroir effect but dependent to human processing. However, an analytical description of the spatial variations of the soil and geological properties, allow to test their relevance for the zonation of wine productions and the justification of the Appellation boundaries

Within the 8 communes of the appellation, vineyards are grown on varied geological substrates, but their distribution is non-random. The mixed carbonate siliciclastic of Coniacian-Santonian age that form the basement of the Beausset syncline are highly favoured for vineyard settlements. Middle and Upper Triassic substrates also seem to be appreciated (figure 3).

\begin{tabular}{lll} 
& Communes of the AOC & Vineyards \\
\hline & $229 \mathrm{~km}^{2}$ & $48 \mathrm{~km}^{2}$ \\
& Percentage & Percentage \\
\hline Coniacian-Santonian & 47 & 77 \\
Cenomanian-Coniacian & 16 & 0 \\
Aptian-Albian & 4 & 1 \\
Berriasian-Barremian & 6 & 0 \\
Upper Jurassic & 7 & 1 \\
Midde Jurassic & 6 & 4 \\
Lower Jurassic & 4 & 2 \\
Triassic & 10 & 14 \\
Permian/Basement & 1 & 1
\end{tabular}

Figure 3 Distribution of geological substrates according to communes and vineyards

The landscape of the area is highly contrasted, from low alluvial plains to steep canyons. The vineyards occupy preferentially the slopes between $2^{\circ}$ and $10^{\circ}$ (figure 4).
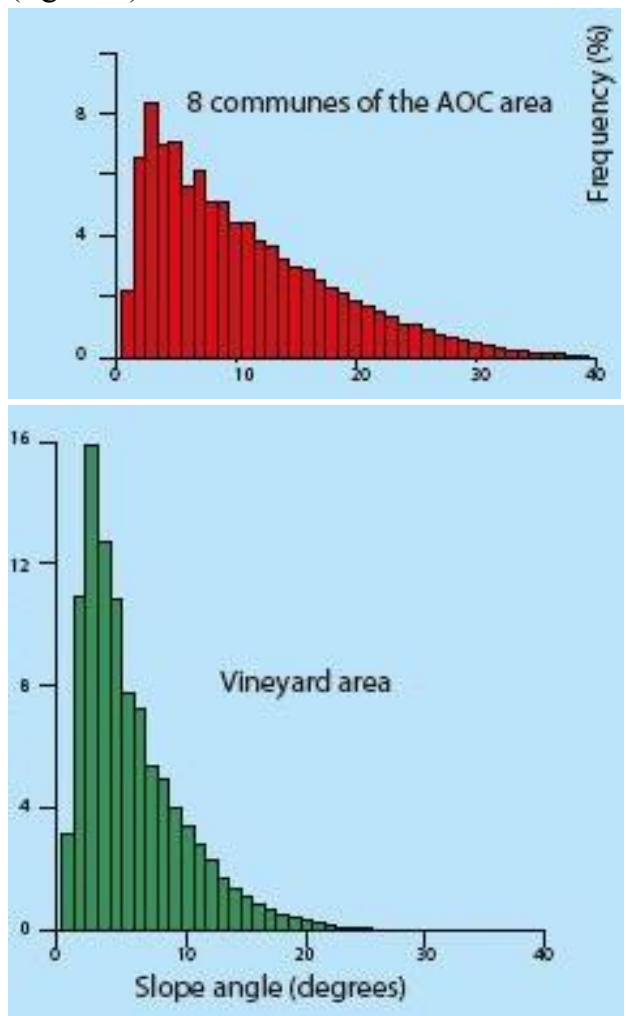

Figure 4. The slopes in the communes of the AOC area and in the vineyard area

Unpublished pedological maps, the 1/50 000 geological maps, complimented with eld-work were used to investigate the link between geology, soil properties and Terroir effect. Statistical analysis of the pedological dataset suggests:

- The lowlands are associated to rich soils, with a high clay component and low level of carbonates. These soils usually fall in the area discarded for production of Bandol wines. 
- The highly permeable, quartz-rich soils derived from alteration of the Coniacian-Santonian calcareous silt- and sandstone house most of the Bandol vineyards. From place to place, the soil properties vary according to grain size (silt to sand), and the input of clay through superficial formations (alluvial and slope deposits).

- The Rudist-rich carbonates produces valuable soils for wine growing on slopes, where soils are thicker and rich in carbonate pebbles and clays.

- In the vineyards, the substrates made of Triassic and Lower Jurassic limestones are usually associated with soils rich in pebbles and fine elements (silt, clay).

The analyses of the geological, soil, and topographic variables allows to the discrimination of potential "Terroir Units" within the Bandol appellation. The
"Terroir Units" can be defined from a set of objective criteria and are therefore operational for zonation. The Terroir effect is potentially significant at the scale of a commercial product and the "Terroir Units" could help for further revision of the AOC zonation. (figure 5).

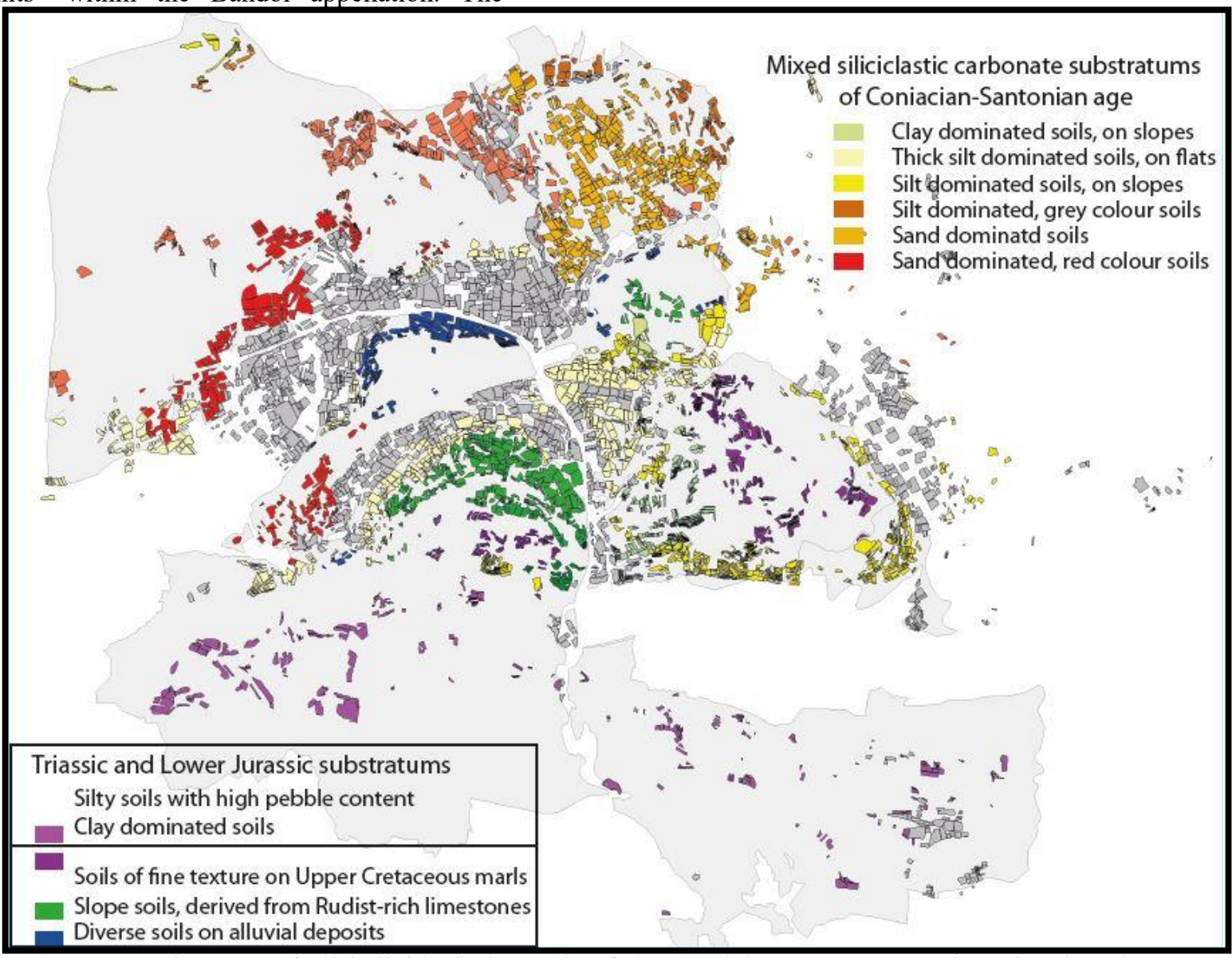

Figure 5. Assignment of all individual vineyards of the Bandol area to a "Terroir Units" based on geological substrate and soil properties

\subsection{The social terroir}

To this relative agro-pedological homogeneity of the vineyard, we can add favorable human factors which allowed the emergence of an appellation of elite from 1941. While the Provence wine was resolutely turned towards the production of mass wines, some visionaries promote the vineyard of Bandol by giving him in his naming decree particularly elitist rules: yields not exceeding $40 \mathrm{hl} /$ ha, choice of a local grape variety, the mourvèdre, in assemblages, obligation of aging in cask of 18 months for the red wines ...

A few decades later the same requirements prevail. The leaders of the vineyard of Bandol systematically refuse any mutation likely to lower the quality of their wines. To cite only one revealing example of a state of mind, they refuse any extension or revision of the bounded Bandol area. They defend every hectare of Bandol in local planning commissions. Finally the technical committee of the appellation makes an important work of improvement and 
harmonization of viticultural practices. Despite the disappearance of tastings during the 2006 reform, the entire production of the 56 cellars and two cooperative cellars is tasted several times a year. 


\section{Territorial regulations in Bandol DOP}

Since 2016, several plots cleared in the forest, have been downgraded by the INAO experts, alerted by the ODG, the organization and defense of the vineyard of Bandol. A terroir study, based on concrete cases, was conducted as part of the downgrading requested by the INAO [4].

It must first be specified that all the settlements of new parcels in the forest are not covered by these procedures. The phenomenon that aims to transfer the vineyards of the plains or hillsides that urbanize towards the wooded margins of the vineyard is not in itself necessarily problematic. For some years the supervisory authorities have even encouraged these practices in certain vineyards particularly affected by land pressure. This "move of viticulture" that has been observed in many vineyards of Provence has sometimes completely transformed some appellations. To cite just one example, mention is made of the Cassis AOC, which no longer corresponds at all to the location of the historic vineyard, classified in 1936.

In the vineyards of Bandol, the implantation of these new parcels has remained limited for the last twenty years. We conducted a landscape diagnostic study of the Bandol vineyard by digitizing the entire plots at different reference dates between 1998 and 2017, as part of the PATERMED scientific program, Mediterranean landscapes and terroirs. [5]. We were able to accurately measure the area of these new parcels planted in the forest. At the scale of the entire vineyard this corresponds to less than $5 \%$ of the planted area of the vineyard in twenty years.

Establishments that are problematic, although rare, must be treated with firmness so as not to harm the image and quality of the wines. At the scale of the whole of Provence three practices appeared these last years, practices sometimes cumulated on the same parcel:

The first problem concerns the spreading of toxic inert products on the lands classified in appellation. This situation results from the importance of major infrastructure works in the region (new roads, tunnels, real estate operations). These spreading of rubble or waste can sometimes reach several meters on a plot of several hectares. The regional press has echoed the problem, viticulture professionals have had to react vigorously to reverse the trend and put in place sanctions within the framework of the DOP (Figure 6).

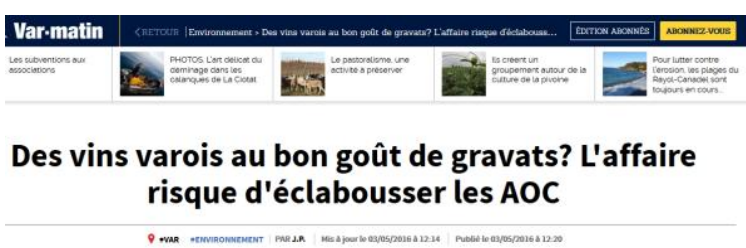

Figure 6. Var matin newspaper (2016/05/03): “Var wines with a good taste of rubble. The case risks splashing the DOP"

The second point that needs to be highlighted is the contribution of exogenous land in parcels classified as AOC. This practice was long tolerated as the land came from the area of appellation. Today the contributions of exogenous lands are no longer accepted by the INAO and the various specifications of the defense and management organizations, ODG are now clear on this point. AOC Bandol is no exception.

Finally, the third and final point is equally worrying is the appearance of quarries in classified wooded areas. Private companies exploit the limestone that is very popular in the construction of villas. The layers are cut several meters thick, sometimes up to 10 or 15 meters (Figure 7).



Figure 7. Extraction of limestone in the vineyard of Bandol

Except for environmental and landscape issues, the development of these quarries poses a real problem for ODG Bandol. When all the rock has been discharged, a plot of vines is laid out in large terraces, using fine particles and crushed rock mobilized on site. New soils appear with agropedological conditions very different from the area classified in production. (Figure 8)

To try to find solutions to these three problems in the vineyard, the following points were discussed to redefine the rules for the development of new vineyards plots. A working group including ODG Bandol and INAO experts is working on the initiative of Olivier Colombano, technical and administrative head of ODG Bandol. 
From what stage of transformation will we consider that the pedological sequence has been too strongly upset? The vineyard soils of Bandol are generally not very thick and very little structured. The development of any new parcels on the slopes involves disturbances in the structure and texture of the soil.

Should hard limestone slabs from plots be crushed or removed? Most soils of the PDO have high $\mathrm{Ph}$, related to the omnipresence of limestone. On-site crushing of the calcareous bedrock has a lasting impact on the soil's chemical properties and is probably not desirable in areas where soil $\mathrm{pH}$ is already high.

In the current state of thinking, the proposal is not to accept soil transformations that include crushing and grinding the hard bedrock, whether it is directly flush, or that it is at a certain depth. Practices that have been tolerated so far include crushing on few decimeters, without disruption of the soil sequence. The topographic profile of the parcel must not be significantly modified.

What are the heights and widths of terraces to remember? The new developments are very spectacular because of their landscape impact compared to traditional practices. Extending the vineyard by destroying the forest is also problematic from the point of view of environmental regulation and sustainable development.

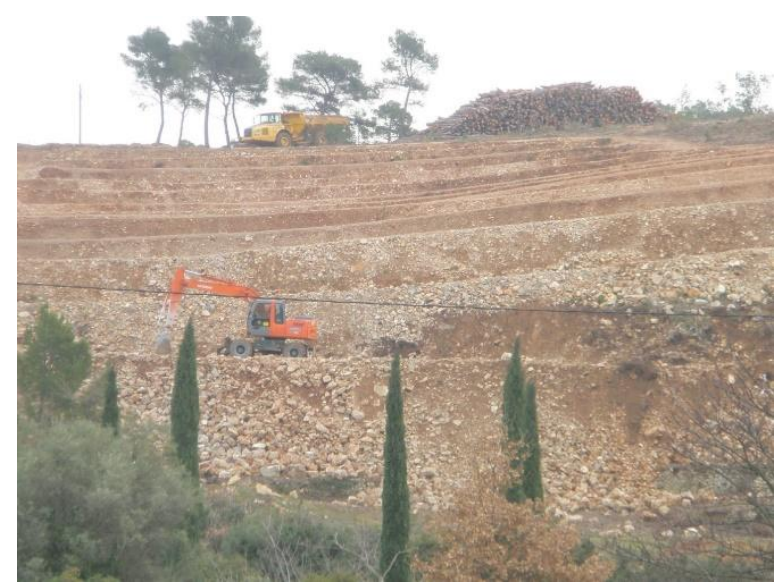

Figure 8: new large terraces in Bandol vineyard

These spectacular landscape transformations in the terraced vineyards have already been observed in many vineyards. For example in the Cinque Terre, one can see new parcels of vines with modernized landscape far from the historical and patrimonial area. At Bandol, the traditional terraces like the sector of Cabassaou or the Tourtine, are separated by walls having a maximum of three meters of height. The width of the terrace is generally less than three meters (three rows or four rows of vines on average). The maximum slope is of the order of $30 \%$. Many terraced plantations, which have emerged for two decades, no longer fit this pattern at all. The proposal of the working group is to accept walls from a height of up to eight meters on slopes that do not exceed $30 \%$. Remember that the Bandol vineyard does not accept the use of the machine to pick up the grapes. It does not need to transform its traditional vine landscape.

The fact of limiting the slope of the wooded parcels that one wishes to plant in vines, is to avoid the cornices having high thicknesses of limestones. They can be developed only with very important means like the quarries already mentioned. Limiting the height of the walls is a way to maintain the traditional landscape character of the vineyard, while allowing some modernization .

In those news plots in forest,the use of irrigationis unavoidable. the water reserves of the soils are much lower than the average of the soils currently exploited. Recall that the use of irrigation in a AOP is tolerated only derogatory in summer by prefectural decree. And still there must be a water resource nearby. We have already exclude the use of allogenic inputs of land. These practices, tolerated in other territories, would be necessary for optimal exploitation of the northernmost PDO territories. These recently invested soils are very little compatible with maintaining the expression of wines according to the current quality standards of AOP. 


\section{Conclusion}

The central question related to these new developments is the maintenance of the typicality of wines. One of the strong points of the Bandol vineyard is the great homogeneity of its products. Homogeneity linked certainly to a welded winegrowing community, but also to a particularly coherent agro-terroir. It therefore seems desirable that the vineyard can be maintained in its current terroirs, even if punctual transformations remain acceptable to compensate for inevitable losses related to urbanization. And these new parcels in the forest must finally develop with a minimum of coherence with the existing vineyard. Indeed besides the question of the rules for the new plots in forest that we posed in this paper, one must also think about the structure of the vineyard exploitations in order to avoid too much fragmentation. This fragmentation of the plot of land causes inevitable movements of agricultural machinery, not compatible with sustainable development of the vineyard.

\section{References}

1. L. Villier, P. Minvielle, A. Fournillon, P.-O. Bruna, Expressions of soil and geological substrate properties in the red wines of Bandol? IXe International Terroirs Congress, Dijon, poster (2012)

2. W. Moran, Crafting terroir: people in cool climates, soils, and markets, Sixth International Cool Climate Symposium for Viticulture and Oenology, Christchurch, 27 p. (2006).

3. G., Flutet et al., Pour une définition opérationnelle au service du développement durable, Actes $d u$ colloque international sur les terroirs, Aix-enProvence, p. 27-32. (2007)

4 F. Gillot, P Minvielle, Ph. Moustier, Rapport d'expertises: procédure de déclassement parcellaire, AOP Bandol, INAO, centre de La Valette, Toulon, 2017, 43 p.

5 P. Minvielle, S. Angles, J. Daligaux, La gouvernance territoriale agricole : l'exemple de la viticulture et de l'oléiculture dans l'agglomération de Toulon (France), Revue Environnement Urbain, Montréal, 6 : 74-99. (2012) 